\title{
In vitro and field efficacy of three fungicides against $F$ usarium bulb rot of garlic
}

\author{
Laura Gálvez Patón • M. Dolores Redondas Marrero • \\ Daniel Palmero Llamas
}

Accepted: 7 November 2016

C Koninklijke Nederlandse Planteziektenkundige Vereniging 2016

\begin{abstract}
Fusarium proliferatum has been identified as the main causal agent of bulb rot of garlic (Allium sativum L.). This disease occurs after the drying process and can rot almost $30 \%$ of the bulbs. Few studies are available regarding the effectiveness of chemical treatments to reduce $F$. proliferatum incidence in garlic. The efficacy of three commercial fungicides of different chemical groups to reduce seven strains of $F$. proliferatum mycelial growth was tested in vitro. These three fungicides were also evaluated by foliar spreading of aqueous suspension in a field crop. Fluopyram $20 \%+$ tebuconazole $20 \%$ and tebuconazole $50 \%$ + trifloxystrobin $50 \%$ were highly effective at reducing mycelial growth in $F$. proliferatum with $\mathrm{EC}_{50}$ values $<2 \mathrm{ppm}$. In general, the effectiveness of the fungicides was enhanced with increasing dosage. Our results indicate that the fungicides evaluated in this study may lead to a risk of resistance appearing in $F$. proliferatum at low concentrations and this risk is maintained at higher doses for the fungicide dimethomorph $7.2 \%+$ pyraclostrobin $4 \%$. Although several of the fungicides affected in vitro mycelial growth
\end{abstract}

L. G. Patón · D. P. Llamas $(\bowtie)$

Department of Agricultural Production, Plant Protection Laboratory, Escuela Técnica Superior de Ingeniería Agronómica, Alimentaria y de Biosistema (ETSIAAB), Technical University of Madrid, Avda. Puerta de Hierro 4, 28040 Madrid, Spain e-mail: daniel.palmero@upm.es

M. D. R. Marrero

Department of Applied Mathematics. Technical University of Madrid, Escuela Técnica Superior Edificación (ETSE), Technical University of Madrid, Av. Juan de Herrera 6, 28040 Madrid, Spain of $F$. proliferatum, as a part of an strategy to measure the efficacy of resistance management it is necessary to monitor the ongoing efficacy of fungicides under commercial conditions. All fungicidal treatments tested in field application failed to control garlic bulb rot during storage.

Keywords Fusarium proliferatum - Mycelial growth . Garlic bulb rot

\section{Introduction}

Garlic (Allium sativum L.) is cultivated worldwide and has been used as a spice and condiment for centuries. Furthermore, numerous therapeutic effects have been reported from garlic consumption, including antioxidant, anti-microbial, anti-diabetic, anti-coagulant, anti-carcinogenic, and immunomodulation activities (IGP Ajo Morado delas Pedroñeras 2016).

Total world garlic production is around 2.42 million $\mathrm{t}$. Spain is the largest producer within the European Union, with $173,600 \mathrm{t}$ in 2013 (FAOSTAT, FAO Statistical Division 2013). Exports from Spain represent $10.77 \%$ of world garlic exports and Spain is the second ranking in world exports of around 269,462 $t$ in 2015 (TRADEMAP, Trade Statistics for International Business Development 2015). Garlic is affected by several fungal diseases, with the most important being rust (Puccinia allii), leaf blight (Stemphylium spp.), pink root (Phoma terrestris), Fusarium basal plate rot (Fusarium spp.), and white rot (Sclerotium ceprivorum). After 
harvest, Penicillium allii and Fusarium spp. are the most frequent pathogenic fungi associated with garlic rot in storage. Among Fusarium spp., F, proliferatum has been identified as the main causal agent of bulb rot. It was first reported in Germany (Seefelder et al. 2002) and later described in the USA (Dugan et al. 2003). Serbia (Stankovic et al. 2007). Spain (Palmero et al. 2010), India (Sankar and Babu 2012). Italy (Tonti et al. 2012). Argentina (Salvalaggio and Ridao 2013), and Egypt (Moharam et al. 2013). This disease occurs after the drying process and can rot almost $30 \%$ of bulbs (Tonti et al. 2012). Rot symptoms consist of superficial dry brown necrotic spots that progress toward the clove and, in some cases. white mycelium and water-soaked symptoms are observed. F proliferatum can colonize garlic roots during crop growth. remain as a latent infection, and develop rot during storage.

Disease control of Fusarium rot of stored garlic is not well established. Although no resistant varieties are available, it is essential to select appropriate plant material to reduce disease incidence. Differential susceptibility of garlic cultivars to $F$. proliferatum has been reported (Palmero et al. 2012, 2013).

Another alternative is to use tissue culture to obtain germplasm free of fungi and viruses, and this is routinely used by many garlic producers in Spain. Thermotherapy (hot water treatment) has also been used pre-sowing to treat seed cloves against fungal. nematode, and mite pests. Palmero et al. (2013) studied the effect of $50^{\circ} \mathrm{C}$ thermotherapy temperature and demonstrated in vitro substantial decreases in conidial viability of $F$. proliferatum. However, practical application of these approaches is not easy: the fungus is protected by external scales, and some of its mycelium has already entered early lesions of the garlic cloves reserved for planting, thus reducing the effectiveness of thermotherapy.

Few studies are available regarding the effectiveness of chemical treatments to reduce Fusarium occurrence in garlic. Miscellaneous fungicide trials have generally failed to demonstrate any effects on $F$ proliferaium. Dugan et al. (2007) reported the effectiveness of benomyl in preventing fungal rot in superficially wounded bulbs. However, this fungicide is currently forbidden in the EU, and alternative fungicides did not provide satisfactory field control. Therefore, it is necessary to explore other control measures for this pathogen. The present study was designed for a threefold purpose: to evaluate the efficacy of three fungicides of different chemical groups to reduce $F$, proliferatum mycelial growth with in vitro trials: to assess the effect of field application of the three fungicides on crop yield: and finally to evaluate the effect on bulb rot during storage of harvested bulbs by reducing early infections in field.

\section{Materials and methods}

In vitro fungicide evaluation

Seven strains of F proliferatum (FPGl-FPG7) were isolated from garlic rot bulbs. Single-spore isolates were identified by morphological and molecular methods. Fungal cultures were maintained on potato dextrose agar (PDA) medium at $4{ }^{\circ} \mathrm{C}$ and in $15 \%$ glycerol at $-80^{\circ} \mathrm{C}$. Three fungicides (Table 1) were evaluated with in vitro assays on PDA medium supplemented with the corresponding fungicide concentrations: $1,10,100$, and $1000 \mathrm{ppm}$. The control assays used PDA medium not supplemented with fungicides.

All plates (including control) were inoculated with a 1-cm-diameter agar plug excised from the actively growing front of 7-days-old colonies of each fungal isolate. Inoculated plates were incubated for $7 \mathrm{~d}$ at $25 \pm 1{ }^{\circ} \mathrm{C}$ in darkness. Each combination of isolate and fungicide concentration was evaluated in four replicate plates. After $7 \mathrm{~d}$ of incubation. colony diameters were measured in two perpendicular directions using a digital scalimeter. The mean of the two colony diameters was used to determine the inhibition percentage of fungal growth compared with the colony diameter of the control plates without fungicide. The experiments were repeated.

\section{Field experiment layout}

Field experiments were conducted at Finca Los Pinares (Ctra. de Motilleja, km 11, Albacete, Spain) from November to July in 2013-2014 and 2014-2015 with supplementary furrow irrigation. Each year, experimental design includes two replications of the three tested fungicides and the untreated control (except for fungicide Cabrio Duo, which was not tested in 2014). The plot size was 1 ha with 20 rows of garlic plants and the space between plots was $1 \mathrm{~m}$; the spacing between rows and plants was 47 and $12 \mathrm{~cm}$, respectively.

The three fungicides were evaluated by aqueous suspension by foliar spreading during crop growth 


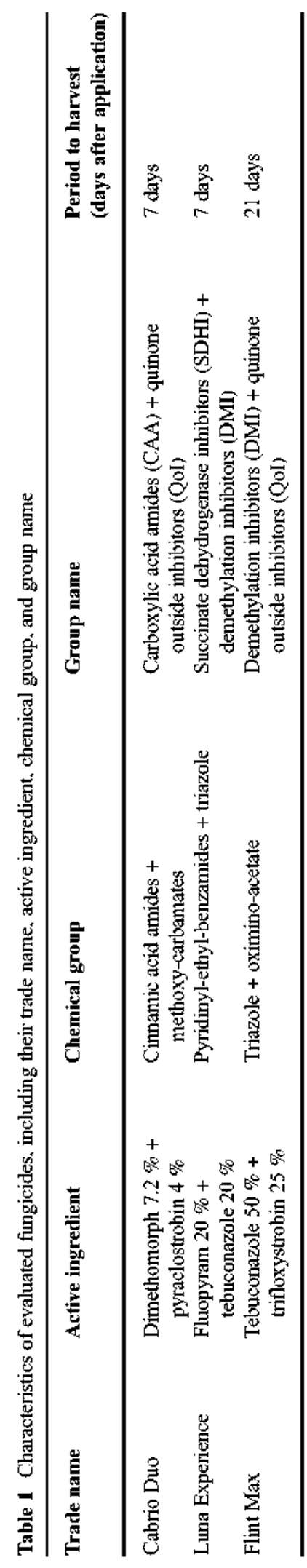

(Table 1). Garlic cultivar 'Morado de Cuenca', widely cultivated in this area. was used in field trials in two consecutive seasons. All garlic cloves used for sowing were pretreated with prochloraz $20 \% w / v$ (Prelude(B). Fungicide treatments were repeated twice a year (May and June). Untreated garlic plants were used as the control.

\section{Disease and weight assessment}

After harvest. bulbs were dried for $10 \mathrm{~d}$ at room temperature and, afterwards, 100 bulbs per plot were weighed. The bulbs were stored for 3 months at room temperature before evaluation of disease incidence. The percentage of symptomatic cloves was evaluated in $50-100$ samples in two replicates (i.e. incidence). Bulbs within each treatment were separated into component cloves. and every clove was rated for rot disease symptoms (i.e. severity). The cloves were graded into four classes: $\mathrm{Nl}=$ no symptoms; $\mathrm{N} 2=$ rotted spots $(\leq 10 \%$ rotted clove $)$; $\mathrm{N} 3$ = partially rooted $(10-50 \%$ rotted clove $)$; and $\mathrm{N} 4=$ highly rotted $(\geq 50 \%$ rotted clove). The rot severity index (RSI) was calculated with the following formula (Palmero et al. 2013):

$$
\mathrm{RSI}=\frac{(\mathrm{N} 1 \times 0)+(\mathrm{N} 2 \times 1)+(\mathrm{N} 3 \times 2)+(\mathrm{N} 4 \times 3)}{\text { number total of garlic cloves }}
$$

A representative sample of 100 bulbs was kept to reisolate Fusarium proliferatum, cloves were surface sterilized for $2-3 \mathrm{~min}$ in $0.5 \% \mathrm{NaOCl}$ in distilled water, rinsed in 4 changes of sterile distilled water and air dried under aseptic conditions. Pieces excised from lesion margins were transferred to potato dextrose agar (PDA). Cultures were incubated at $25^{\circ} \mathrm{C}$ in the dark. Five to seven days later. single spore cultures were obtained from Fusarium colonies emerging from the infected tissues and examined morphologically. The taxonomic criteria of Nelson et al. (1983), Gerlach and Nirenberg (1982) and Leslie and Summerell (2006) were followed.

\section{Statistical analyses}

All data analyses were performed with IBM SPSS software (version 21.0: New York. USA). The in vitro evaluation data for fungicide were analyzed statistically using analysis of variance (ANOVA) and regression analyses. Post-hoc analyses were performed using 
Tukey's test. In all cases, $p<0.05$ was the significance level. Percentage inhibition was plotted against $\sqrt{\log }$ fungicide concentration for each fungicide and was fitted to a linear regression. Subsequently, the effective concentration at which mycelial growth showed $50 \%$ inhibition ( $\left.\mathrm{EC}_{50}\right)$ was also calculated. In vitro fungicide evaluation data were tested for normality, homogeneity of variance, independence, and linearity.

Disease (incidence and severity) and weight data were subjected to ANOVA. For the RSI analysis data, unaffected cloves were excluded. Log (RSI +0.1 ) transformation was applied to comply with normality. homogeneity of variance. and independence of data.

\section{Results}

In vitro effects of fungicides on mycelial growth of $\mathbf{F}$. Proliferatum

The $F$. proliferatum isolates had different sensitivities according to the evaluated fungicide (Table 2). Flint $\mathrm{Max}(\mathrm{B})$ was the most effective fungicide with $\mathrm{EC}_{50}$ value $<1$ ppm, together with Luna Experience(B) with a slightly higher $\mathrm{EC}_{50}$ of $1.02 \mathrm{ppm}$. Cabrio Duo(B) was also effective at low concentration with $\mathrm{EC}_{50}<3$ ppm (Table 2). According to the effective concentration for each active ingredient, all five active ingredients were effective at low concentration with $\mathrm{EC}_{50}<0.0020 \mathrm{nM}$. Fluopyram and trifloxistrobin were the most effective active ingredient with $E c_{50}$ of $0.0005 \mathrm{mM}$. The effect of replication was not significant $(p=0.158$ ) on inhibition of mycelial growth. The effects of the three fungicides tested, concentration. and isolate as well as their interactions on fungal growth were significant $(p<0.001)$.

$E_{70}$ and $E C_{90}$ were always higher than the respective $\mathrm{EC}_{50}$ for each fungicide. Flint Max and Luna Experience had $\mathrm{EC}_{70}<\mathbf{4}$ ppm (Table 2) but $\mathrm{EC}_{70}$ for Cabrio Duo was markedly higher. Attending to the active ingredients, again those included in Flint Max and Luna Experience (tebuconazole, fluopyran and trifloxystrobin) had low $\mathrm{Ec}_{70} \leq 0.002 \mathrm{mM}$ but those included in Cabrio Duo showed slightly higher $\mathrm{EC}_{70}$ $(0.174 \mathrm{mM}$ for Dimethomorph and $0.096 \mathrm{mM}$ for pyraclostrobin). Similarly, for EC 90. Flint Max and Luna Experience had EC 90 values of 29.03 and 56.47 ppm, respectively, but Cabrio Duo did not reach $90 \%$ inhibition at the highest rate tested with $\mathrm{Ec}_{90}$ calculated values for both active ingredients that exceed $5000 \mathrm{mM}$.

The results of tests conducted with 1 ppm Luna Experience and Flint Max showed inhibition of $\mathbf{4 6 . 0 1}$ and $61.61 \%$ of mycelial growth relative to the control (Fig. 1A); inhibition increased with dose, reaching $98 \%$ inhibition with $100 \mathrm{ppm}$. Increasing doses of Cabrio Duo improved the inhibition (slope $=18.45$ ), reaching about $70 \%$ inhibition of mycelial growth with the highest concentration tested (1000 ppm). The concentration of fungicide had a highly significant effect on mycelial growth inhibition $(p<0.001)$.

In terms of the response of isolates to concentrations tested. Luna Experience and Flint Max fungicides followed the same pattern, with low concentrations tested showing major differences among isolates. even at $1 \mathrm{ppm}$ (Fig. IC and D). In contrast, the differences among the isolates remained generally constant in response to different doses of Cabrio Duo (Fig. 1B).

\section{Postharvest parameters}

The mean dry weight of the bulbs was close to $60 \mathrm{~g}$ bulb $^{-1}$, which would amount to about $9 \mathrm{tha}^{-1}$. The effect of replication was not significant $(p=0.557)$ on dry weight per bulb. The effect of fungicide treatment was also not significant ( $p=0.123$ ) and the effect of year was marginally significant $(p=0.065)$ (Table 3 ).

The incidence percentage of garlic with some symptoms of clove rot was higher in the control compared with the two fungicides evaluated in the first year of testing (Table 3). There were no differences between treatments in the second year of testing, with all treatments having incidence rates $>75 \%$. The effect on rot incidence of garlic was not significant for replication $(p=0.157)$ and fungicide treatment $(p=0.119)$. The effect of year was highly significant $(p \leq 0.001)$.

The RSI values obtained in 2014-2015 were higher. They almost doubled values obtained in 2013-2014 (Table 3 ). The effect on garlic bulb rot severity was not significant for replication $(p=0.182)$; however: year was highly significant $(p<0.001)$.

\section{Discussion}

In vitro test results showed that Flint Max was the most effective fungicide at inhibiting mycelial growth, followed by Luna Experience. Both fungicides contain 
Table $2 \mathrm{EC}$ values (ppm) and the regression equations of $F$ proliferatum isolates on PDA media supplemented with the evaluated fungicides

\begin{tabular}{|c|c|c|c|c|c|c|}
\hline Fungicide & $\mathbf{r}$ & $\mathbf{R}^{2}(\%)$ & Regression equation* & $\mathrm{EC}_{50}$ *** & $\mathrm{EC}_{70}$ *** & $\mathrm{EC}_{90} * *$ \\
\hline Cabrio Duo & 0.87 & 75.5 & $y=38.20(0.85)+18.45(0.69) x$ & 2.56 & 934.80 & $>1000$ \\
\hline Flint Max & 0.94 & 87.7 & $y=61.65(0.68)+23.44(0.56) x$ & $<1$ & 1.34 & 29.03 \\
\hline Luna Experience & 0.95 & 90.8 & $y=46.68(0.82)+32.73(0.67) x$ & 1.02 & 3.22 & 56.47 \\
\hline
\end{tabular}

* $y=$ percentage of mycelial growth inhibition; $x=\sqrt{\log c o n c e n t r a t i o n ~(p p m)}$. Data brackets show the standard deviation of the parameter estimation. **: Calculated by the concentration equation (ppm)

the same active ingredient, tebuconazole, which is a demethylation inhibitor (DMI) fungicide.

DMI fungicides are a chemically diverse group that acts by inhibition of the demethylation step in sterol biosynthesis, which is needed in fungal cell walls. Marin et al. (2013) determined EC50 and EC90 for tebuconazole and $F$. proliferatum from wheat to be 0.50 and $10.00 \mathrm{ppm}$, respectively. Ivić et al. (2011) recorded EC50 for tebuconazole in the range of $0.85-2.57 \mathrm{ppm}$ for $F$. graminearum, $0.85-1.58 \mathrm{ppm}$ for $F$ avenaceum, and $0.22-0.85$ ppm for $F$. verticillioides. In a similar experiment, EC50 values for tebuconazole and different
Fusarium isolates were 0.24-6.5 ppm (Müllenborn et al. 2008). The EC50 values were within the same range as those obtained in the present study. However, the EC90 value obtained by Marin et al. (2013) was 3-6 times lower than our results. According to the active ingredients, both of the most effective fungicides contain the demethylase inhibitor tebuconazole (at concentrations of $0.0016 \mathrm{mM}$ in Flint max and $0.0007 \mathrm{mM}$ in Luna Experience). Pasquali et al. (2013) report that epoxiconazole and tebuconzole (DMI) inhibited F. culmorum by $50 \%$ at concentrations of $0.0142 \pm 0.0030$ and $0.0041 \pm 0.0012 \mathrm{mM}$, respectively.
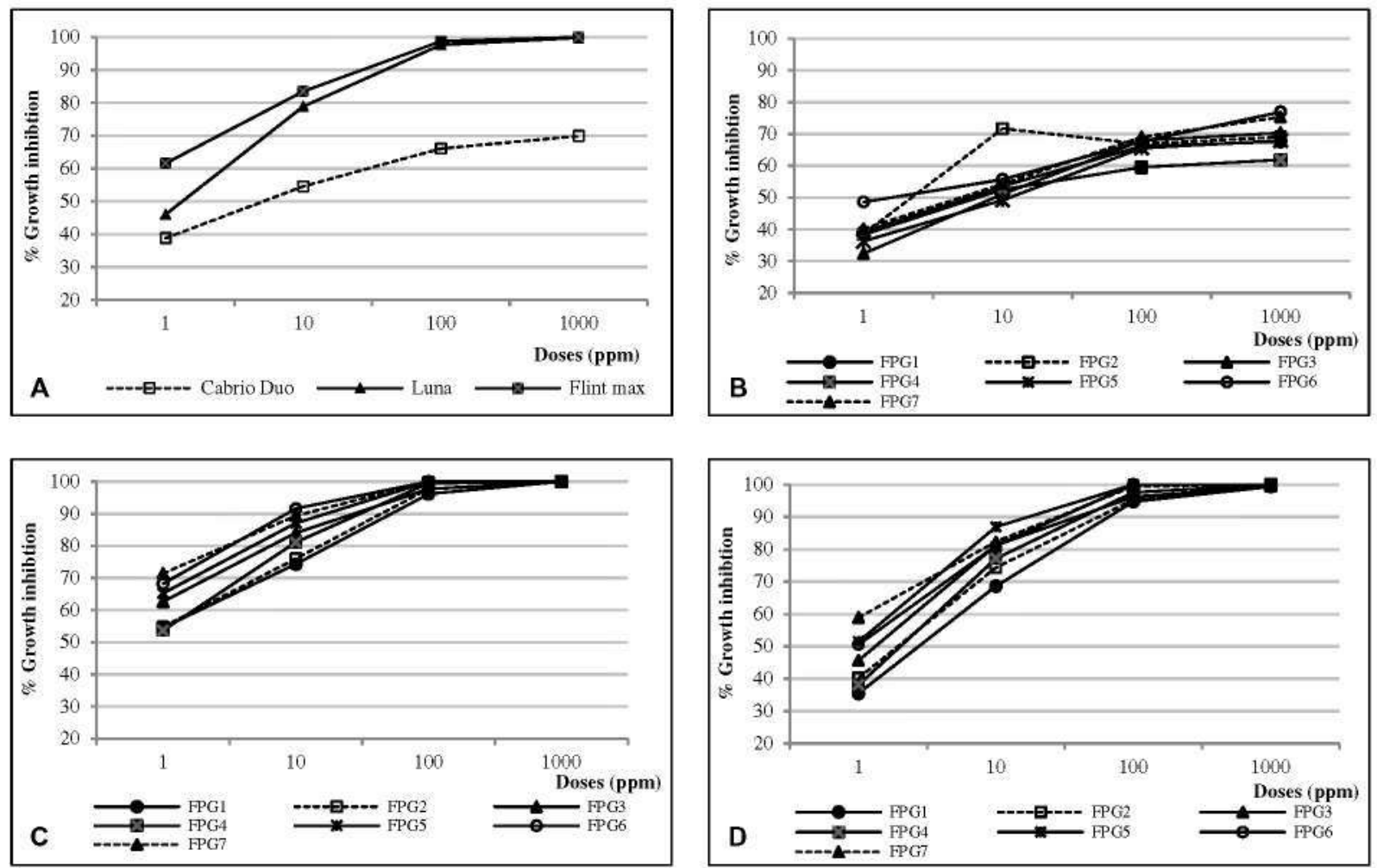

Fig. 1 Effect of fungicide (Cabrio Duo, Flint Max, and Luna) dose on the percent inhibition of mycelial growth for $F$. proliferatum isolates FPG1-FPG7. a According to fungicide; b Cabrio Duo for fungal isolates; $\mathbf{c}$ Flint Max for fungal isolates; d Luna Experience for fungal isolates 
Table 3 Results of the weight per bulb, incidence of affected bulbs, and rot severity index (RSI) for each fungicide in the 2014 and 2015 field trials

\begin{tabular}{|c|c|c|c|c|c|}
\hline \multirow[t]{2}{*}{ Fungicide } & \multirow{2}{*}{$\begin{array}{l}\text { Dry weight per bulb }(g) \text { Mean } \pm \text { SD } \\
2014 / 2015\end{array}$} & \multicolumn{2}{|c|}{ Incidence (\%) Mean \pm SD } & \multicolumn{2}{|c|}{ RSI* Mean \pm SD } \\
\hline & & 2014 & 2015 & 2014 & 2015 \\
\hline Cabrio Duo & $56.75 \pm 16.25 \mathrm{a}$ & NT & $73.04 \pm 8.04 \mathrm{a}$ & NT & $0.31 \pm 0.29 \mathrm{a}$ \\
\hline Luna Experience & $55.03 \pm 16.05 \mathrm{a}$ & $50.00 \pm 11.79 \mathrm{a}$ & $79.36 \pm 3.22 \mathrm{a}$ & $0.25 \pm 0.33 \mathrm{a}$ & $0.35 \pm 0.31 \mathrm{a}$ \\
\hline Flint Max & $57.42 \pm 15.67 \mathrm{a}$ & $49.00 \pm 7.19 \mathrm{a}$ & $81.63 \pm 38.91 \mathrm{a}$ & $0.21 \pm 0.20 \mathrm{a}$ & $0.44 \pm 0.31 \mathrm{a}$ \\
\hline No fungicide & $57.13 \pm 16.26 \mathrm{a}$ & $77.08 \pm 2.95 \mathrm{~b}$ & $76.00 \pm 11.78 \mathrm{a}$ & $0.20 \pm 0.24 \mathrm{a}$ & $0.41 \pm 0.24 \mathrm{a}$ \\
\hline Significance & $p=0.123$ & $p=0.005$ & $p=0.564$ & $p=0.423$ & $p=0.113$ \\
\hline
\end{tabular}

*RSI was graded into four classes ( 0 -4) from no symptoms to highly rotted of each garlic clove

The same letter within columns indicates no significant difference at $p<0.005$. NT Not tested

Data for dry weight per bulb are treated as combined data for year 2014 and 2015 (the effect of year was not significant $(p=0.065)$ )

In our work, the active ingredient tebuconazole was evaluated together with another active ingredient (fluopyram or trifloxystrobin). Fluopyram is a modern fungicide included in the biochemical mode of action $\mathrm{C}$ (respiration) by the FRAC ( 2016), belonging to the succinate dehydrogenase inhibitor (SDHI) group. Recently, it was reported to be effective in controlling different plant pathogens (Fought et al. 2011; Avenot et al. 2012; Amiri et al. 2014). In the case of trifloxystrobin, there is little literature available assessing its effect against Fusarium spp. Maitlo et al. (2014) evaluated the fungicide Nativo ${ }^{\circledR}$ (tebuconazole + trifloxystrobin) at different doses (1-1000 ppm) to control $F$ oxysporum $\mathrm{f}$. sp. ciceris, and their results agree with our results for Flint Max, which has the same active ingredients. Pasquali et al. (2013) demonstrated that the complex II and complex III respiration inhibitors isopyrazam (SDHI) and trifloxystrobin (Qol) were unable to inhibit $F$. culmorum up to a concentration of $1 \mathrm{mM}$. Trifloxystrobin concentrations $\leq 0.0003 \mathrm{mM}$ neither inhibited $F$. graminearum significantly (Dubos et al. 2011). Trifloxystrobin was unable to reduce fungal growth to $50 \%$ for the vast majority of strains.

Maitlo et al. (2014) also evaluated the active ingredient dimethomorph, obtaining markedly lower percentages of inhibition ( $41.75 \%$ at $1000 \mathrm{ppm})$ than those obtained for Cabrio Duo in the present study $(69.87 \%$ at $1000 \mathrm{ppm}$ ). This increased sensitivity may be due to the effect of another active ingredient (pyraclostrobin) included in Cabrio Duo.

Chen et al. (2012) evaluated the in vitro activity of pyraclostrobin in inhibiting mycelial growth of $126 \mathrm{~F}$. asiaticum isolates and $63 \mathrm{~F}$. graminearum isolates: $\mathrm{EC}_{50}$ was in the range of $0.012-0.135$ and $0.010-$
$0.105 \mu \mathrm{g} \mathrm{mL}^{-1}$, respectively. However, $\mathrm{EC}_{50}$ values of our analysis for $F$. proliferatum causing rot garlic were always higher (3.59 ppm).

When comparing groups of fungicides, several studies have indicated greater efficacy of DMI fungicides. Within this group, the triazol chemical group (e.g. prothioconazole, cyproconazole, and tebuconazole; Müllenborn et al. 2008) and azoles (e.g. prochloraz, difenoconazole, and fluquinconazole; Amini and Sidovich 2010) have proved more effective against Fusarium spp. than strobilurin fungicides (e.g. azoxystrobin and kresoxim-methyl) based on $\mathrm{EC}_{50}$ and $\mathrm{EC}_{90}$ values. In fact, Dubos et al. $(2011,2013)$ and Pasquali et al. (2013) described Fusarium species are sensitive towards fungicides belonging to the group of DMI such tebuconazol, but are intrinsically resistant towards complex III respiration inhibitors (QoI) such trifloxystrobin and the SDHI. Attending to this results, it seems that the inhibitory effects detected in the present study are mainly borne on the tebuconazole.

The differences observed among the isolates for two of the three fungicides tested (Luna Experience and Flint Max) decreased with increasing dose. However, the results for Cabrio Duo differed among the isolates remained even at the highest concentrations tested. Our results indicate that the fungicides evaluated in this study may lead to a risk of resistance appearing in $F$. proliferatum at low concentrations and this risk is maintained at higher doses for Cabrio Duo. However, mixtures of different active ingredients within different chemical groups reduce the risk of fungicide resistance developing (Brent and Hollomon 2007). Our results revealed the effectiveness of several fungicides in inhibiting mycelial growth of $F$. proliferatum, although 
all fungicidal treatments tested failed to control garlic bulb rot during storage. Dugan et al. (2007) found that although results of miscellaneous fungicide trials sometimes attained significant control (e.g. benomyl, fludioxonil and thiophanate methyl), some experiments failed to demonstrate any effect on bulb rot control. This suggests that there were factors other than fungicide effectiveness contributing to this problem. Among the factors to consider for adequate control of soil diseases in the field are the date of application of fungicides, the number of applications, environmental conditions, pressure of inoculum in soil, and the nature and concentration of fungicides applied (Vyas 1988; Schwartz and Mohan 2008; Marin et al. 2013). Our results showed a clear correlation between the trial year and the severity of rot of garlic cloves. This allows us to presuppose other factors: not only the amount of initial inoculum in fields (Dugan et al. 2007; Palmero et al. 2011) but also the environmental conditions during cultivation and storage of garlic after harvesting, specifically the conditions of relative humidity and temperature during the process of drying bulbs (Palmero et al. 2013).

The period of drying in the field after harvest (about $7 \mathrm{~d}$ ) and the long period of storage of the product before sale (more than a month) can explain the limited effectiveness of the tested fungicides in controlling postharvest rot.

There are unanswered questions regarding disease control. It seems important to know the relationship between the amount of inoculum in soil and postharvest disease severity to plan crop rotations. Environmental conditions such as relative humidity and temperature during early drying and storage are likely to be other key factors in managing this disease.

Acknowledgments This research was supported by the Garlic Cooperative Coopaman SCL (Spain) Project P1520290111.

\section{References}

Amini, J., \& Sidovich, D. (2010). The effects of fungicides on Fusarium oxysporum f. Sp. lycopersici associated with fusarium wilt of tomato. Joumal of Plant Protection Research, 50(2), 172-178.

Amiri, A., Heath, S. M., \& Peres, N. A. (2014). Resistance to fluopyram, fluxapyroxad, and penthiopyrad in Botrytis cinerea from strawberry. Plant Disease, 98(4), 532-539.

Avenot, H. F., Thomas, A., Gitaitis, R. D., Langston Jr., D. B., \& Stevenson, K. L. (2012). Molecular characterization of boscalid- and penthiopyrad-resistant isolates of Didymella bryoniae and assessment of their sensitivity to fluopyram. Pest Management Science, 68(4), 645-651.

Brent, K. J., \& Hollomon, D. W. (2007) Fungicide resistance in crop pathogens: how can it be managed?. FRAC Monograph No. 1, Brussels. Crop Life International.

Chen, Y., Zhang, A. F., Gao, T. C., Zhang, Y., Wang, W. X., \& Ding, K. J. (2012). Integrated use of pyraclostrobin and epoxiconazole for the control of Fusarium head blight of wheat in Anhui Province of China. Plant Disease, 96(10), 1495-1500.

Dubos, T., Pasquali, M., Pogoda, F., Hoffmann, L., \& Beyer, M. (2011). Evidence for natural resistance towards trifloxystrobin in fusarium graminearum. European Journal of Plant Pathology, 130, 239-248.

Dubos, T., Pasquali, M., Pogoda, F., Casanova, A., \& Hoffmann, L. (2013). Differences between the succinate dehydrogenase sequences of isopyrazam sensitive Zymoseptoria tritici and insensitive fusarium graminearum strains. Pesticide Biochemistry and Physiology, 105(1), 28-35.

Dugan, F., Hellier, B., \& Lupien, S. (2003). First report of Fusarium proliferatum causing rot of garlic bulbs in North America. Plant Pathology, 52(3), 426-426.

Dugan, F., Hellier, B., \& Lupien, S. (2007). Pathogenic fungi in garlic seed cloves from the United States and China, and efficacy of fungicides against pathogens in garlic germplasm in Washington state. Journal of Phytopathology, 155(7-8), 437-445.

FAOSTAT (FAO Statistical Division) (2013). http://faostat3.fao. org/download/Q/QC/E. Accessed 14 April 2016.

Fought, L., Musson, G. H., \& H. Young (2011). Fluopyram fungicides for the control of diseases of horticultural and row crops. (pp. S54). Phytopathology, 101: S54.

FRAC (Fungicide Resistance Action Committee). (2016). FRAC Code List 2016: Fungicides sorted by mode of action. http://www,frac.info/docs/default-source/publications/fraccode-list/frac-code-list-2016.pdf?'sfvrsn=2.

Gerlach W.L. \& Nirenberg H. (1982). The genus Fusarium. A pictorial atlas. Mitt. Biol Bundesanst. Land-Forstwirtsch. Berlin-Dahlen 209, 1-406.

IGP Ajo Morado delas Pedroñeras. (2016). Accessed 7 September 2016.

Ivić, D., Sever, Z., \& Kuzmanovska, B. (2011). In vitro sensitivity of Fusarium graminearum, $F$, avenaceum and $F$ verticillioides to carbendazim, tebuconazole, flutriafol, metconazole and prochloraz. Pesticidi i fitomedicina, 26(1), 3542.

Leslie, J. F., \& Summerell, B. A. (2006). The fusarium laboratory manual. Ames, Iowa, USA: Blackwell Publishing.

Maitlo, S., Syed, R., Rustamani, M., Khuhro, R., \& Lodhi, A. (2014). Comparative efficacy of different fungicides against fusarium witt of chickpea (Cicer arietinum L.). Pakistan Journal of Botany, 46(6), 2305-2312.

Marin, P., de Ory, A., Cruz, A., Magan, N., \& González-Jaen, M. T. (2013). Potential effects of environmental conditions on the efficiency of the antifungal tebuconazole controlling Fusarium verticillioides and Fusarium proliferatum growth rate and fumonisin biosynthesis. International Journal of Food Microbiology, 165(3), 251-258.

Moharam, M. M. A., Farrag, E. S. H., \& Mohamed, M. D. A. (2013). Pathogenic fungi in garlic seed cloves and first report of Fusarium proliferatum causing cloves rot of stored bulbs 
in upper Egypt. Archives of Phvtopathologv and Plant Protection, 46(17), 2096-2103.

Müllenborn. C., Steiner, U., Ludwig. M., \& Oerke. E. C. (2008). Effect of fungicides on the complex of Fusarium species and saprophytic fungi colonizing wheat kernels. European Journal of Plant Patholog; 120(2), 157-166.

Nelson, P. E., Toussoun, T. A., \& Marasas, W. F. O. (1983). Fusarium species: an ilhustrated manual for identification. University Park, PA. USA: Pennsylvania State University Press.

Palmero, D., De Cara. M., Iglesias, C., Moreno, N., Gonzalez, M. T., \& Tello, J. (2010), First report of Fusarium proliferatum causing rot of garlic bulbs in Spain. Plant Disease, 94(2), 277.

Palmero, D.. de Cara, M., Gálvez L., \& Tello, J. (2011). Effect of pre-sowing treatment on postharvest garlic rot caused by Fusarium proliferatum. In International Congress of Postharvest Pathologv, Lleida. Spain (pp. 156).

Palmero, D, de Cara. M., Nosir, W. Gálvez, L., Cruz, A.. \& Woodward. S. (2012). Fusarium proliferatum isolated from garlic in Spain: identification, toxigenic potential and pathogenicity on related allium species. Phytopathologia Mediterranea, 5](1), 207-218.

Palmero, D., Galvez, L.. Garcia. M., Gil, J., \& Benito, S. (2013). The effects of storage duration, temperature and cultivar on the severity of garlic clove rot caused by Fusarium proliferatum. Postharvest Biology and Technologv, 78, 34-39.

Pasquali, M., Spanu. F., Scherm. B., Balmas. V. Hoffmann. L., Hammond-Kosack, K. E., Beyer, M.. \& Migheli. Q. (2013). FeStuA from Fusarium culmorm controls wheat foot and root rot in a toxin dispensable manner. PloS One, 8(2), e57429.

Salvalaggio, A. E., \& Ridao, A. C. (2013). First report of Fusarium proliferatum causing rot on garlic and onion in Argentina. Plant Disease, 97(4), 556.

Sankar, N. R., \& Babu. G. P. (2012). First report of Fusarium proliferatum causing rot of garlic bubs (Allium sativu) in India. Plant Disease, 96(2), 290.

Schwartz, H. F., \& Mohan. S. K. (2008). Compendium of onion and garlic diseases and pests (127 pp). Ed. APS Press.

Seefelder. W., Gossmann. M.. \& Humpf. H. U. (2002). Analysis of fumonisin Bl in Fusarium proliferatum infected asparagus spears and garlic bulbs from Germany by liquid chromatography-electrospray ionization mass spectrometry. Journal of Agricultural and Food Chemistry, 50(10), 27782781.

Stankovic, S., Levic, J., Petrovic, T., Logrieco, A.. \& Moretti. A. (2007). Pathogenicity and nycotoxin production by fusarium proliferatum isolated from onion and garlic in Serbia. European Joumal of Plant Pathologv, 118(2), 165-172.

Tonti. S., Prà, M. D., Nipoti, P., Prodi, A., \& Alberti. I. (2012). First report of Fusarium proliferatum causing rot of stored garlic bulbs (Allium sativum L.) in Italy. Joumal of Phytopathologv, 160(11), 761-763.

TRADEMAP (Trade Statistics for International Business Development). (2015). http:/www.trademap.org/Country SelProductCountry_TS.aspx?nvpm $=1|724||| 070320|| 6|1| 1 \mid \overline{2}$ |2|1|2|1|1. Accessed 14 April 2016

Vyas. S. C. (1988). Nontarget effects of agricultural fungicides. London, UK: CRC Press. 